\title{
Nitrogênio em soja: qualidade fisiológica das sementes
}

Nitrogen in soybean: physiological quality of seeds

\section{Letícia Barão Medeiros *}

Universidade Federal de Pelotas, Brasil

\section{Geison Rodrigo Aisenberg}

Universidade Federal de Pelotas, Brasil

\section{Márcio Peter}

Universidade Federal de Pelotas, Brasil

\section{Jéssica Mengue Rolim}

Universidade Federal de Pelotas, Brasil

\section{Tiago Zanatta Aumonde}

Universidade Federal de Pelotas, Brasil

\section{Tiago Pedó}

Universidade Federal de Pelotas, Brasil

\section{Revista de la Facultad de Agronomía}

Universidad Nacional de La Plata, Argentina

ISSN: 1669-9513

Periodicidade: Semestral

vol. 120, núm. 1, 2021

redaccion.revista@agro.unlp.edu.ar

Recepção: 04/05/20

Aprovação: 03/03/21

URL: http://portal.amelica.org/ameli/jatsRepo/23/232004004/index.html

DOI: https://doi.org/10.24215/16699513e066

*Autor correspondente: lele-medeiros@hotmail.com 


\title{
Resumo
}

O objetivo deste estudo foi avaliar os componentes de rendimento e de qualidade fisiológica de sementes de soja cultivadas com aplicação de diferentes doses e épocas de aplicação de nitrogênio. $O$ delineamento inteiramente casualizado, em esquema fatorial 4x2 (quatro doses de nitrogênio e duas épocas de aplicação), com quatro repetições. A aplicação de nitrogênio foi feita na forma de uréia ( $45 \%$ de $\mathrm{N}$ ), nas doses de $0,25,50$ e $75 \mathrm{~kg} \mathrm{~N}^{-1}$ durante a semeadura e no estádio R4 da cultura. Foi avaliado o número de vagens por planta, o número de sementes por planta, a massa de mil sementes, primeira contagem de germinação, porcentagem de germinação, massa seca de parte aérea e raiz. A aplicação de nitrogênio influenciou positivamente nos parâmetros de rendimento da

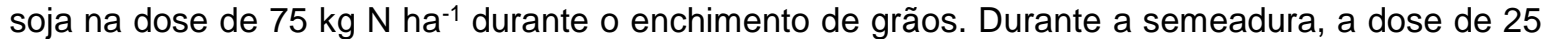
$\mathrm{kg} \mathrm{N}^{-1}$ resultou em maiores médias da massa seca de parte aérea, $50 \mathrm{~kg} \mathrm{~N} \mathrm{ha}^{-1}$ incrementou a massa de mil grãos e massa seca de raiz e a aplicação de $75 \mathrm{~kg} \mathrm{~N} \mathrm{ha}^{-1}$ na semeadura durante a primeira safra obteve resultados positivos para a primeira contagem de germinação e germinação. Para os resultados da segunda safra, a aplicação de $50 \mathrm{~kg} \mathrm{~N} \mathrm{ha}^{-1} \mathrm{em}$ semeadura proporcionou incremento da primeira contagem de germinação.

Palavras-chave: Glycine max, componentes de rendimento, adubação nitrogenada, doses de nitrogênio, época de adubação

\begin{abstract}
The objective of this study was to evaluate the yield and physiological quality components of soybean seeds grown with application of different doses and times of application of nitrogen. The completely randomized design, in a $4 \times 2$ factorial scheme (four nitrogen doses and two application times) with four repetitions. The application of nitrogen was done in the form of urea $(45 \% \mathrm{~N})$, in the doses of 0 , 25,50 e $75 \mathrm{~kg} \mathrm{~N} \mathrm{ha}^{-1}$ during sowing and at the R4 stage of the culture. The number of pods per plant, the number of seeds per plant, the mass of a thousand seeds, first germination count, percentage of germination, dry mass of aerial part and root were evaluated. The application of nitrogen positively influenced the parameters of soybean yield at the dose of $75 \mathrm{~kg} \mathrm{~N} \mathrm{ha}^{-1}$ during grain filling. During sowing, the dose of $25 \mathrm{~kg} \mathrm{~N}^{-1}$ resulted in higher averages of the dry mass of aerial part, $50 \mathrm{~kg} \mathrm{~N}$ ha-1 increased the mass of one thousand grains and dry root mass and the application of $75 \mathrm{~kg} \mathrm{~N}$ $\mathrm{ha}^{-1}$ at sowing during the first harvest obtained positive results for the first germination and germination count. For the results of the second crop, the application of $50 \mathrm{~kg} \mathrm{~N} \mathrm{ha}^{-1}$ at sowing provided an increase in the first germination count.
\end{abstract}

Keywords: Glycine max, yield components, nitrogen fertilization, nitrogen doses, fertilization season 


\section{INTRODUÇÃO}

A soja (Glycine max (L.) Merrill) é a oleaginosa mais cultivada no mundo. Além de ser fonte de óleo e proteína, esta cultura é rica em carboidratos, minerais e vitaminas do complexo B (Faria et al., 2018). O Brasil é o segundo maior produtor desta leguminosa, sendo considerada a principal cultura econômica do agronegócio brasileiro, ocupando uma área total de 35,8 milhões de hectares semeados na safra 2018/2019 (CONAB, 2019).

Os aumentos de rendimentos desta cultura estão relacionados às boas práticas de manejo, sendo 0 equilíbrio de nutrientes fundamental para o bom desenvolvimento de plantas. A utilização de compostos minerais pode interferir nos níveis de nutrientes orgânicos presente nas plantas, influenciando em processos fisiológicos ou bioquímicos (Ferreira et al., 2006).

Por ser uma leguminosa, a maior parte da demanda de nitrogênio da soja é suprida pela fixação biológica, por meio da simbiose com bactérias do gênero Bradyrhizobium (Amado et al., 2010) e o restante, por meio da mineralização da matéria orgânica do solo (Bahry et al., 2014). Contudo, através do melhoramento genético e inovações no sistema de cultivo, o potencial de produtividade da cultura da soja vem crescendo no decorrer dos anos. Deste modo, a complementação com nitrogênio mineral pode ser necessária para suprir as necessidades da cultura para obtenção de altas produtividades (Pierozan et al., 2015).

Na cultura da soja, o nutriente mais limitante é o nitrogênio $(N)$, que participa do processo de crescimento vegetal e está presente na formação de aminoácidos, proteínas, enzimas e na molécula de clorofila (Nogueira et al., 2010). Sua deficiência pode ocasionar problemas como baixo teor de proteínas nos grãos, clorose de folhas mais velhas em decorrência da diminuição da produção de clorofila, progredindo para necrose (EMBRAPA, 2010).

Através da fertilização nitrogenada é possível observar aumento no número de vagens da planta de soja (Silva et al., 2011) e nos níveis de proteína do grão de feijão (Gomes Júnior \& Sá, 2010). Entretanto, ainda é preciso estabelecer a compreensão do efeito da adubação nitrogenada na fisiologia da planta, para se estabelecer um equilíbrio entre a adição de nitrogênio e a fixação biológica (Brito et al., 2015).

Deste modo, o objetivo deste estudo foi avaliar os componentes de rendimento e de qualidade fisiológica de sementes de soja cultivadas com aplicação de diferentes doses e épocas de aplicação de nitrogênio.

\section{METODOLOGIA}

O experimento foi realizado na Universidade Federal de Pelotas e as análises no laboratório de Fisiologia de Sementes do Programa de Pós-Graduação em Ciência e Tecnologia de Sementes da Faculdade de Agronomia Eliseu Maciel, localizada geograficamente a $31^{\circ} 52^{\prime} \mathrm{S}$ e $52^{\circ} 21^{\prime} \mathrm{W}$. O clima da região caracterizase por ser temperado, com chuvas distribuídas e verão quente, classificado por Köppen em Cfa. Os dados de temperatura, umidade relativa e de radiação solar foram obtidos a partir do boletim da Estação Agroclimatológica de Pelotas, localizada próximo ao local de cultivo (Figura 1).

A semeadura foi realizada em vasos de polietileno preto contendo substrato de solo com as seguintes características químicas e físicas: $\mathrm{pH}$ (H2O), 5,4; P, 15,5 mg dm-3; K, 54 mg dm-3; Ca, 2,8 cmolc dm-3; Mg, 0,5 cmolc dm-3; Al, 0,4 cmolc dm-3; Fe, 1.400 mg dm-3; Cu, 0,3 mg dm-3; Zn, 0,9 mg dm-3; Mn, 27,0 mg dm-3; CTC, 6,0 cmolc dm-3; saturação de base, 54\%; matéria orgânica, 1,4\%; argila, 15\%. Previamente à semeadura realizou-se a correção do substrato de acordo com as análises do solo e baseada no Manual Brasileiro de Fertilização (CQFS, 2004).

O experimento foi realizado na segunda quinzena de novembro, nos anos agrícolas de 2013/2014 e 2014/2015, com a cultivar de soja BMX Potência RR e irrigação feita manualmente conforme a exigência da cultura.

Utilizou-se o delineamento experimental inteiramente casualizado para a produção de sementes e o mesmo também foi utilizado em laboratório. Os tratamentos consistiram em quatro doses de nitrogênio $(0$, 25, 50 e $75 \mathrm{~kg} \mathrm{~N} \mathrm{ha}^{-1}$ ) aplicados na semeadura e no enchimento (estádio R4) em esquema fatorial $4 \times 2$ (doses $x$ estádio) com quatro repetições, sendo utilizado uréia $(45 \% \mathrm{~N})$ como fertilizante nitrogenado. 

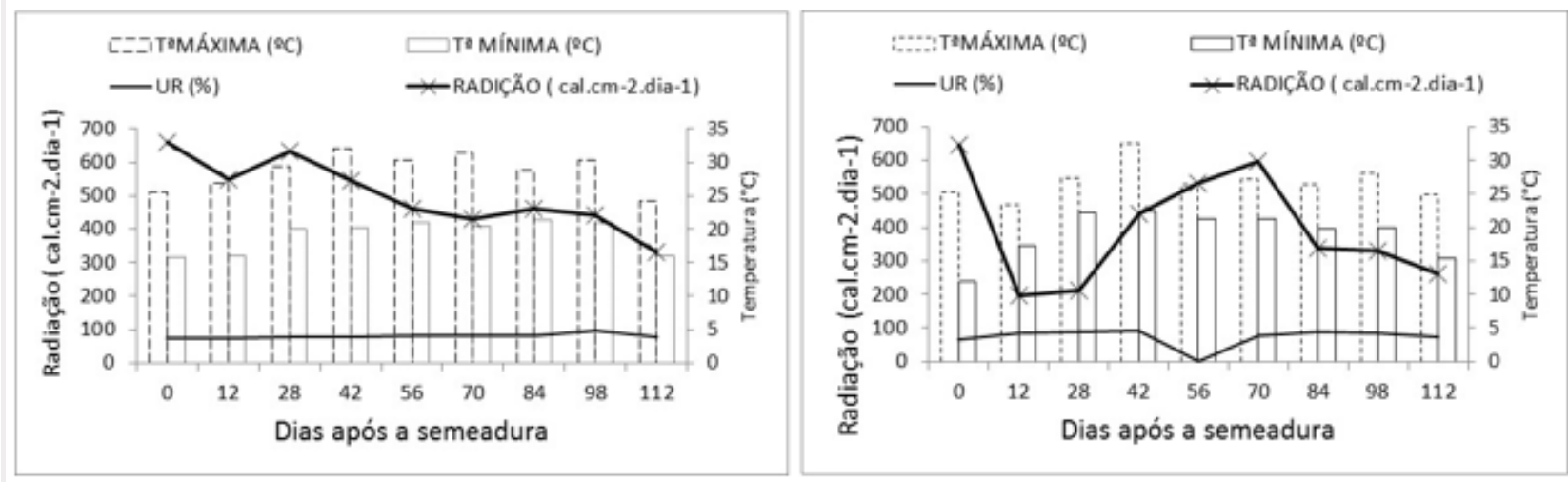

Figura 1

Radiação solar, temperatura máxima, temperatura mínima e umidade relativa do ar durante a primeira (a) e segunda (b) safra do experimento.

A colheita e a trilha foram realizadas manualmente, com teor de água das sementes de $16 \%$. Após o beneficiamento, através do método de estufa a $105^{\circ} \mathrm{C}$ por $24 \mathrm{~h}$, o teor de água foi aferido, atingindo $12 \%$.

Para a avaliação dos parâmetros de rendimento, foram avaliados o número de vagens $(\mathrm{NVg})$ e sementes (NSm) por planta, obtidos através de contagem direta. A massa de mil sementes (M1000) foi avaliada através de oito repetições de 100 sementes (MAPA, 2009).

Para a avaliação da qualidade fisiológica, as análises realizadas foram:

Teste de germinação (G): Realizado com quatro repetições de 25 sementes, em rolos de papel "germitest" formados por três folhas, com umidade de 2,5 vezes o peso do papel seco. Os rolos foram transferidos para a câmara de germinação do tipo B.O.D. a uma temperatura constante de $25^{\circ} \mathrm{C}$ e fotoperíodo de $12 \mathrm{~h}$. As avaliações foram realizadas aos sete dias após a semeadura e os resultados expressos em porcentagem de plântulas normais (MAPA, 2009).

Primeira contagem de germinação (PCG): Conduzido juntamente com o teste de germinação, a contagem foi realizada aos cinco dias após a semeadura, conforme as Regras para Análise de Sementes. Os resultados foram expressos em porcentagem de plântulas normais.

Massa seca de parte aérea (WPA) e raiz (WR) de plântulas: Obtida ao final do teste de germinação através da aferição da massa de quatro amostras de oito plântulas. Para a secagem, as plântulas foram alocadas em envelopes de papel pardo e colocadas em estufa de ventilação forçada sob temperatura de $70^{\circ} \mathrm{C}$ por $72 \mathrm{~h}$. Os resultados foram expressos em miligramas por órgão.

Os dados foram submetidos à análise da variância e, se significativos pelo teste $\mathrm{F}$ a nível $5 \%$ de probabilidade, as médias foram comparadas através de regressão polinomial.

\section{RESULTADOS}

Através dos resultados obtidos pela análise da variância somente a massa de mil obteve diferença significativa para a interação entre os fatores.

O número de vagens por planta não apresentou diferença significativa para as doses de $\mathrm{N}$ aplicadas na semeadura (Figura 2a). No enchimento, doses de $\mathrm{N}$ aumentaram linearmente o número de vagens por planta (Figura 2a), sendo obtido com elevado coeficiente de determinação $\left(R^{2} \geq 0,86\right)$, favorecendo 0 pegamento e posterior enchimento de vagens, devido à disponibilidade deste nutriente na fase de desenvolvimento. 


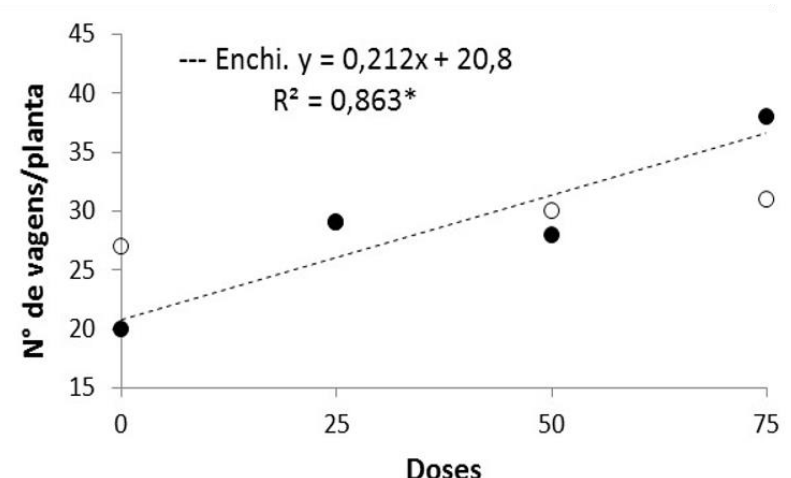

Doses
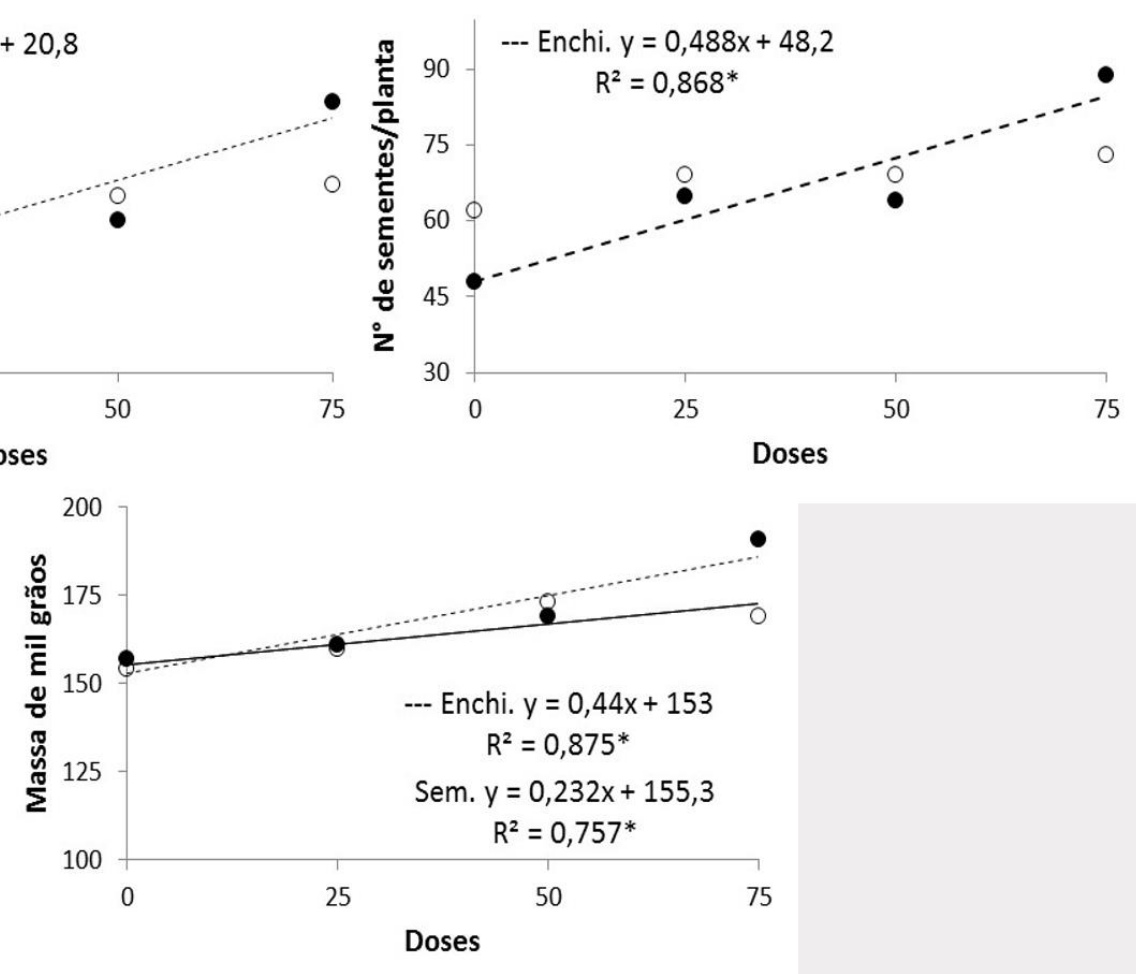

\section{Figura 2}

Número de vagens por planta (a), número de sementes por planta (b) e massa de mil grãos (c) em resposta a diferentes doses e épocas de aplicação de adubação nitrogenada. Aplicação na semeadura (-) e no enchimento de sementes (- - -).

O número de sementes por planta não apresentou diferença significativa quando se aplicou nitrogênio durante a semeadura. No enchimento de grãos, a aplicação de $\mathrm{N}$ apresentou diferença significativa, indicando incremento linear em função das diferentes doses (Figura 2b). A aplicação da dose de $75 \mathrm{~kg} \mathrm{~N}$ ha $^{-1}$ apresentou a maior média (89), seguida de 65, 64 e 48 para as doses de 25,50 e $0 \mathrm{~kg} \mathrm{~N} \mathrm{ha}^{-1}$, respectivamente.

A massa de mil grãos apresentou valores significativos para as duas épocas de aplicação (Figura 2c). Tanto para a aplicação em semeadura, como para a aplicação no enchimento de grãos, a adubação nitrogenada apresentou crescimento linear de acordo com o aumento das doses, indicando o efeito benéfico da aplicação de nitrogênio para essa variável no presente estudo.

Através dos resultados obtidos pela análise da variância pode-se observar que houve efeito significativo da época de aplicação de nitrogênio em relação a primeira contagem de germinação, germinação e matéria seca de parte aérea. Em relação ao efeito das diferentes doses aplicadas e da interação dos fatores, todas as variáveis observadas apresentaram efeito significativo para as médias obtidas na primeira safra (Tabela 1). Para as médias da segunda safra, a época de aplicação apresentou efeito significativo somente para a variável massa seca de raiz. As médias das doses de nitrogênio foram significativas para primeira contagem de germinação e massa seca de parte aérea, e a interação entre os fatores não apresentou efeito significativo somente para a massa seca de parte aérea (Tabela 1). 


\section{Tabela 1}

Resumo da análise da variância com quadrado médio da primeira contagem de germinação (PCG), germinação (G), massa seca de parte aérea (Wpa) e massa seca de raiz (Wr). Equações de regressão referentes aos parâmetros de rendimento produzidos sob diferentes doses e épocas de aplicação da adubação nitrogenada.

\begin{tabular}{|c|c|c|c|c|c|}
\hline \multirow[t]{2}{*}{$\mathrm{CV}$} & \multirow[t]{2}{*}{$\overline{G L}$} & \multicolumn{3}{|c|}{ QM } & \multirow[b]{2}{*}{ Wr } \\
\hline & & PCG & $\mathrm{G}$ & Wpa & \\
\hline & & \multicolumn{4}{|c|}{ Safra 13/14 } \\
\hline Epoca (E) & 1 & $128^{*}$ & $648^{*}$ & $118.3^{*}$ & $0.002^{\mathrm{ng}}$ \\
\hline Doses (D) & 3 & $1972^{*}$ & $133.3^{*}$ & $89.02^{*}$ & $18.88^{*}$ \\
\hline ExD & 3 & $4428^{*}$ & $688^{*}$ & $198.92^{*}$ & $88.15^{\star}$ \\
\hline Resíduo & 21 & 12.82 & 10.47 & 1.33 & 1.48 \\
\hline \multirow[t]{2}{*}{$\overline{C V}(\%)$} & & 3,7 & 4,8 & 4,4 & 11,9 \\
\hline & & \multicolumn{4}{|c|}{ Safra 14/15 } \\
\hline Epoca (E) & 1 & $32^{\text {ns }}$ & $6.13^{\mathrm{n}}$ & $2.50^{\mathrm{ns}}$ & $53.12^{*}$ \\
\hline Doses (D) & 3 & $49.33^{*}$ & $2.75^{\mathrm{n}}$ & $18.77^{\star}$ & $3.70^{\text {ns }}$ \\
\hline ExD & 3 & $169.33^{*}$ & $27.38^{*}$ & $11.43^{\text {n5 }}$ & $9.90^{\star}$ \\
\hline Resíduo & 21 & 10.51 & 6.83 & 5.89 & 2.73 \\
\hline CV $(\%)$ & & 3.71 & 2,68 & 7.66 & 15.45 \\
\hline
\end{tabular}

"Médias seguidas por "*” são significativas em nível de 5\% de probabilidade do erro através da análise de regressão. Médias seguidas por "ns" não diferem entre si em nível de 5\% de probabilidade do erro através da análise de regressão.

A primeira contagem de germinação obteve efeito significativo para as duas épocas de aplicação de nitrogênio (Figura 3a e Figura3b). Na primeira safra, a aplicação durante a semeadura apresentou comportamento quadrático, com elevado coeficiente de determinação $\left(R^{2} \geq 0,90\right)$, em que a dose de $75 \mathrm{~kg}$ $\mathrm{N} \mathrm{ha}^{-1}$ apresentou a maior média (96\%) e o tratamento sem aplicação de $\mathrm{N}, 0 \mathrm{~kg} \mathrm{~N}^{-1}$, a menor média (14\%). No enchimento de grãos, a maior média ocorreu na dose $0 \mathrm{~kg} \mathrm{~N} \mathrm{ha}^{-1}(88 \%)$, seguida por $50 \mathrm{~kg} \mathrm{~N}$ ha $^{-1}(77 \%), 75 \mathrm{~kg} \mathrm{~N} \mathrm{ha}^{-1}(71 \%)$ e $25 \mathrm{~kg} \mathrm{~N} \mathrm{ha}^{-1}$ (70\%) (Figura 3a).

As médias da primeira contagem de germinação para aplicação de $\mathrm{N}$ na semeadura durante a segunda safra apresentaram comportamento quadrático (Figura 3b), obtendo a maior média no tratamento em que foram aplicados $50 \mathrm{~kg} \mathrm{~N} \mathrm{ha}^{-1}$ (97\%) e menores com aplicação de $0 \mathrm{~kg} \mathrm{~N} \mathrm{ha}^{-1}$ (81\%). Durante o enchimento de grãos a aplicação de nitrogênio obteve médias inferiores comparadas à dose $0 \mathrm{~kg} \mathrm{~N} \mathrm{ha}^{-1}$ (Figura $3 \mathrm{~b}$ ).

A germinação de sementes de soja apresentou diferença significativa para as doses de nitrogênio aplicadas na semeadura, com comportamento quadrático e elevado coeficiente de determinação (R2 $\geq$ 0,97). A maior porcentagem de germinação ocorreu com a dose de $75 \mathrm{~kg} \mathrm{~N}^{-1}$ (99\%), decrescendo conforme a diminuição das doses para 98, 95 e $76 \%$ para as doses de 50, 25 e $0 \mathrm{~kg} \mathrm{~N} \mathrm{ha}^{-1}$, respectivamente. Para a aplicação de $\mathrm{N}$ durante $\mathrm{o}$ enchimento de sementes, não houve diferença significativa entre as médias da primeira safra (Figura 3c)

$\mathrm{Na}$ segunda safra, as médias obtidas para germinação apresentaram diferença significativa somente na aplicação de nitrogênio realizada no enchimento de sementes. A dose de $75 \mathrm{~kg} \mathrm{~N} \mathrm{ha}^{-1}$ obteve o mesmo valor da média do tratamento controle, com $0 \mathrm{~kg} \mathrm{~N}^{-1}(99 \%)$, seguidas por $25 \mathrm{~kg} \mathrm{~N}^{-1}(96 \%)$ e $50 \mathrm{~kg} \mathrm{~N}$ ha $^{-1}(94 \%)$ (Figura 3d). 

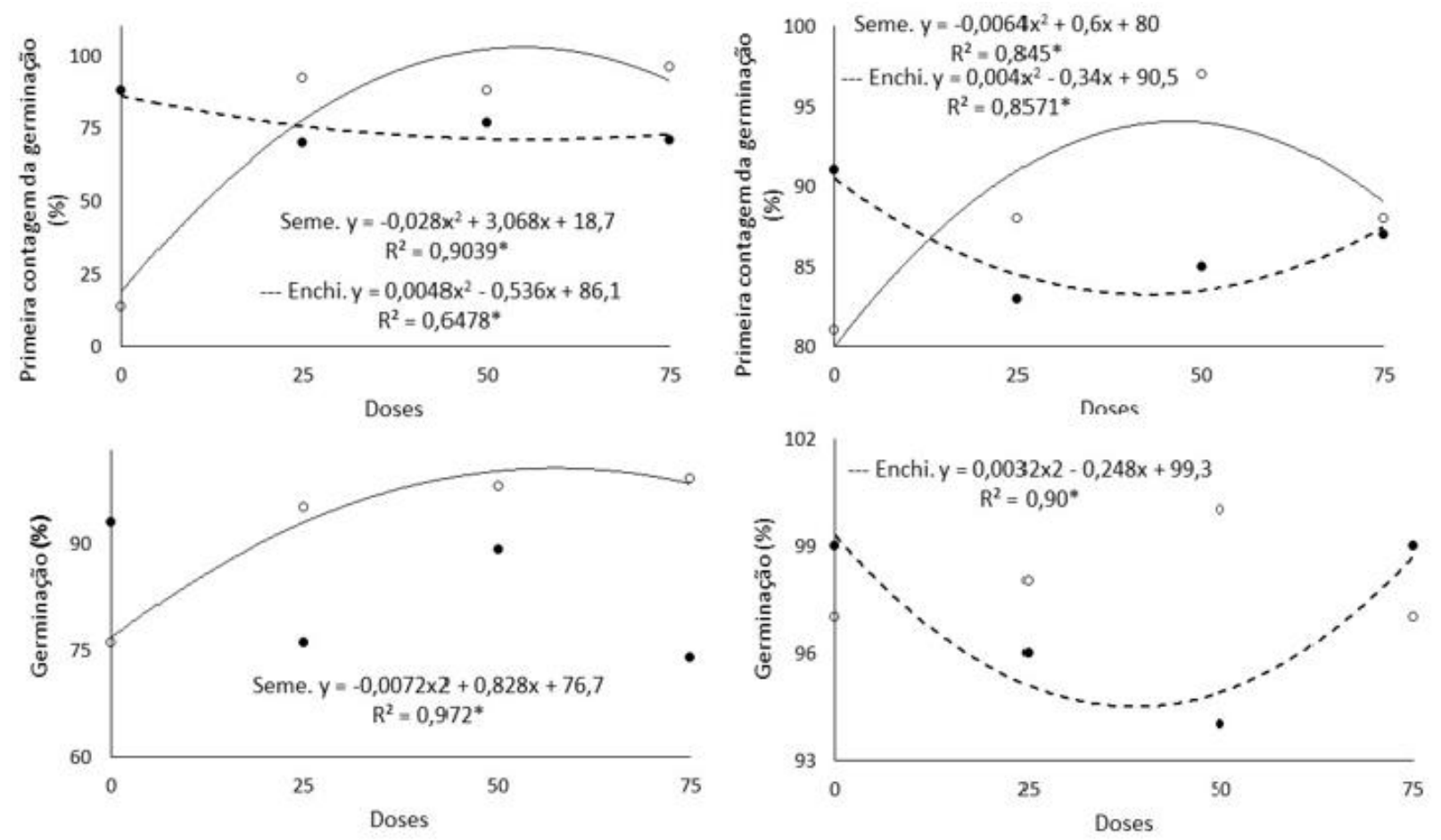

Figura 3

Primeira contagem de germinação da safra 2013/2014 (a) e 2014/2015 (b), germinação da safra 2013/2014 (c) e 2014/2015 (d) em resposta a diferentes doses e épocas de aplicação de adubação nitrogenada. Aplicação na semeadura (-) e no enchimento de sementes (- - -).

A matéria seca de parte aérea (Wpa) apresentou diferença significativa somente para a aplicação de nitrogênio na semeadura durante a primeira safra, com elevado coeficiente de determinação $(R 2 \geq 0,97)$, indicando que a aplicação de diferentes doses de nitrogênio contribuiu para o acréscimo de Wpa (Figura 4a). Para os resultados de massa seca de parte aérea obtidos durante a segunda safra, a adubação de $\mathrm{N}$ não apresentou diferença significativa para nenhuma das épocas de aplicação.

A produção de matéria seca de raiz na primeira safra apresentou diferença quando se aplicou, na

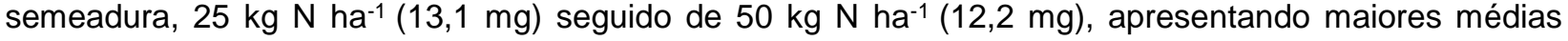
quando comparados a não fertilização $0 \mathrm{~kg} \mathrm{~N} \mathrm{ha}^{-1}(6,6 \mathrm{mg})$ e a aplicação de $75 \mathrm{~kg} \mathrm{~N} \mathrm{ha}^{-1}(9,1 \mathrm{mg})$. Para a aplicação no enchimento de sementes os resultados não apresentaram diferença significativa (Figura 4b). Os resultados obtidos para as médias de produção de matéria seca de raiz durante a segunda safra apresentaram diferença significativa para aplicação de $\mathrm{N}$ durante a semeadura (Figura 4c). A aplicação de nitrogênio, independente da dose, se mostrou menos efetiva do que a não fertilização, decrescendo linearmente. 


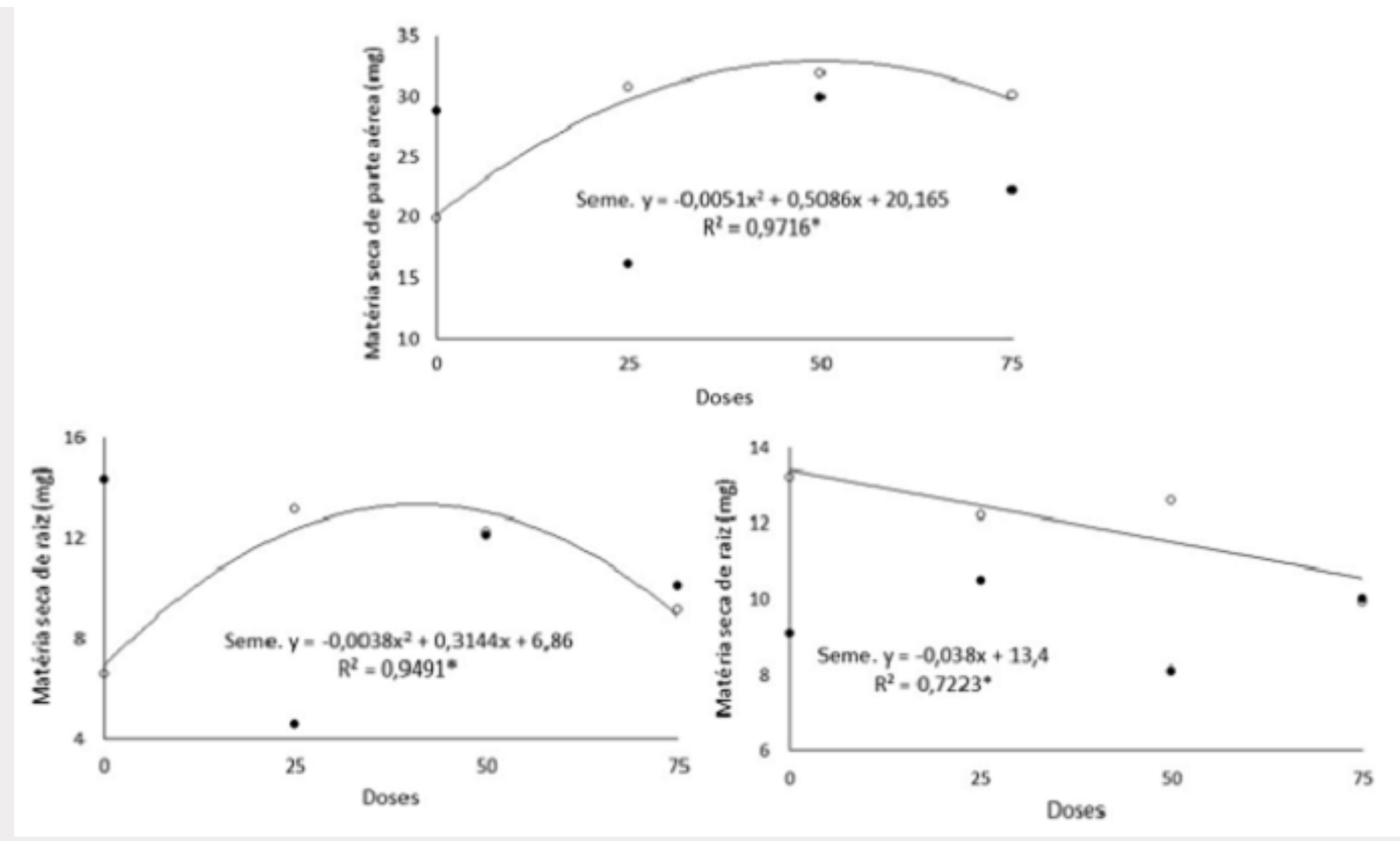

Figura 4

Matéria seca de parte aérea da safra 2013/2014 (a), matéria seca de raiz da safra 2013/2014 (b) e 2014/2015 (c) em resposta a diferentes doses e épocas de aplicação de adubação nitrogenada durante a safra 2014/2015. Aplicação na semeadura (-) e no enchimento de sementes (- - -).

\section{DISCUSSÃo}

O número de vagens é considerado um importante componente de rendimento, pois contribui na translocação de fotoassimilados, sustentação e proteção das sementes durante o processo de formação até a maturação. Petter et al. (2012) ao aplicarem doses de 20 e $40 \mathrm{~kg} \mathrm{~N} \mathrm{ha}^{-1} \mathrm{em}$ adubação tardia em soja, observaram aumento no número de vagens por planta em todas as cultivares avaliadas no estudo.

Em relação ao número de sementes por planta, Bahry et al. (2014), ao aplicarem nitrogênio em soja no estádio R5.2, observaram maior número de grãos por vagem no terço inferior da planta $(2,19)$, quando comparado ao tratamento controle $(1,96)$ e a aplicação em R5.4 $(1,96)$. Através da capacidade das plantas de apresentarem maior índice de área foliar em sua fase reprodutiva, a maior taxa de produção de fotossíntese pode contribuir para uma maior retenção de legumes na cultura da soja (Bahry et al., 2013), contribuindo para um maior número de grãos no final do ciclo.

A variável massa de mil apresentou valores significativos para a aplicação de nitrogênio, indicando efeito benéfico para o presente estudo. Marcon et al. (2017) ao aplicarem uma fonte de nitrogênio líquido (32\%) na soja em cobertura, em que a primeira dose foi aplicada no estádio R1 (início do florescimento) e a segunda dose em R3 (formação da vagem), $4 \mathrm{~L} \mathrm{~N} \mathrm{ha-1}$, observaram aumento na massa de mil grãos para a cultivar TMG 7062 IPRO. Segundo Zimmer et al. (2012), a aplicação de nitrogênio após o florescimento da cultura é canalizada, na maioria das vezes, diretamente para a produção de grãos. 
A primeira contagem de germinação apresentou valores significativos para a aplicação de nitrogênio na semeadura referente as duas safras estudadas. Desta forma, a aplicação de nitrogênio antes do período reprodutivo pode refletir em plantas que produzirão sementes com maior vigor, conforme descrito por Alsenberg et al. (2018), aumentando a velocidade e uniformidade da germinação.

A aplicação de nitrogênio na semeadura na primeira safra deste estudo obteve valores significativos para a variável germinação. Como a fixação biológica tem início somente após a emergência das plântulas, essa chamada adubação "de arranque", realizada na semeadura, pode beneficiar o desenvolvimento inicial da soja (Uhry, 2010).

Durante a primeira safra, a aplicação de nitrogênio durante a semeadura incrementou a produção de matéria seca de parte aérea. Em experimento realizado por Pereira et al. (2018), os autores também encontraram aumento de massa seca de parte aérea com a aplicação de nitrogênio na semeadura e nos estádios iniciais da soja, antes da floração.

Segundo Parente et al. (2015), a aplicação de doses superiores a $20 \mathrm{~kg} \mathrm{~N}^{-1} \mathrm{~h}^{-1}$ possuem a capacidade de afetar o potencial produtivo da soja, pois podem influenciar negativamente a produção de nódulos da raiz, dificultando a fixação biológica de nitrogênio. Desta maneira, conforme os resultados obtidos neste trabalho para a massa seca de plântulas de soja durante a segunda safra, a aplicação de doses de $\mathrm{N}$ não se mostraram efetivas para um maior desenvolvimento inicial de plântulas.

A disponibilidade de radiação solar é um dos fatores que mais interferem no crescimento e desenvolvimento de plantas. Os valores médios de radiação solar durante a primeira safra (2013/2014) foram maiores quando comparados à segunda safra (Figura 1). Este fato pode ter causado interferência no aproveitamento da adubação nitrogenada na safra 2014/2015 neste estudo, explicando as diferenças na germinação e matéria seca de raiz e parte aérea quando se aplicou nitrogênio na semeadura somente para os resultados obtidos na primeira safra.

\section{CONCLUSÃO}

A aplicação da adubação nitrogenada nas doses de 50 e $75 \mathrm{~kg} \mathrm{ha}^{-1}$ se mostraram eficientes em grande parte das avaliações realizadas neste estudo. As aplicações durante o período de semeadura implicaram, de modo geral, em maiores médias dos parâmetros referentes à qualidade fisiológica das sementes, já as aplicações realizadas no enchimento (R4) contribuíram nos parâmetros de rendimento. Através dos resultados obtidos neste experimento é possível observar que a aplicação de nitrogênio pode se mostrar eficiente em alguns parâmetros da cultura, dependendo do ano agrícola. Desta maneira se faz necessário a realização de mais estudos sobre o assunto.

\section{REFERÊNCIAS}

Aisenberg, G.R., F. Koch, J.R. Pimentel, C. Troyjack, Í.T.P. Dubal, L.A. Santos, G.H. Demari, V.J. Szareski, F.A. Villela, E.G. Martinazzo, T. Pedó \& T.Z. Aumonde. 2018. Soybean growth, solar energy conversion and seed vigour affected by different nitrogen $(\mathrm{N})$ doses. Australian Journal of Crop Science 12(03): 343-349.

Amado, T.J.C., J.A. Schleindwein \& J.E. Fiorin. 2010. Manejo do solo visando à obtenção de elevados rendimentos de soja sob sistema plantio direto. In: Thomas AL \& Costa JA (Eds.) Soja Manejo para alta produtividade de grãos. Porto Alegre, UFRGS. pp. 35-97.

Bahry, C.A., E. Venske, M. Nardino, S.S. Fin, P.D. Zimmer, V.Q. Souza \& B.O. Caron. 2013. Características morfológicas e componentes de rendimento da soja submetida à adubação nitrogenada. Revista Agrarian 6(21): 281-288.

Bahry, C.A., M. Nardino, E. Venske, S.S. Fin, P.D. Zimmer, V.Q. Souza \& B.O. Caron. 2014. Efeito do nitrogênio suplementar sobre os componentes de rendimento da soja em condição de estresse hídrico. Revista Ceres 61(2): 155-160.

Brito, L.F.D., R.S. Pacheco, B.F.D. Souza Filho, E.P.D.B. Ferreira, R. Straliotto \& A.P. Araújo. 2015. Response of common bean to rhizobium inoculation and supplemental mineral nitrogen in two Brazilian Biomes. Revista Brasileira de Ciência do Solo 39(4): 981-992. 
CONAB. 2019. Acompanhamento da Safra Brasileira de Grãos 2018/2019 - Sétimo Levantamento Junho/2019, v.6 - Brasília: Conab, Disponível em: https://www.conab.gov.br/infoagro/safras/graos/boletim-da-safra-de-graos> Último acesso: junho 2019.

CQFS. 2004. Manual de adubação e calagem para os Estados do Rio Grande do Sul e Santa Catarina, $10^{\underline{a}}$ ed, Sociedade Brasileira de Ciência do Solo. Comissão de Química e Fertilidade do Solo, Porto Alegre. $400 \mathrm{pp}$.

EMBRAPA (Empresa Brasileira de Pesquisa Agropecuária). 2010. Disponível em:<https://www.infoteca.cnptia.embrapa.br/bitstream/doc/859439/1/Doc322online1.pdf> Último acesso: junho 2019.

Faria, L.A., J.M. Peluzio, W.F. Santos, C.M. Souza, G.A. Colombo \& F.S. Afférri. 2018. Oil and protein content in the grain of soybean cultivars at different sowing seasons. Revista Brasileira Ciências Agrárias 13(2): 518.

Ferreira, M.M.M., G.B. Ferreira, P.C.R. Fontes \& J.P. Dantas. 2006. Qualidade do tomate em função de doses de nitrogênio e da adubação orgânica em duas estações. Horticultura Brasileira 24: 141145.

Gomes Júnior, F.G. \& M.E. Sá. 2010. Proteína e qualidade de sementes de feijão (Phaseolus vulgaris L.) em função da adubação nitrogenada em plantio direto. Revista Brasileira de Sementes 32: 34-44.

MAPA. Ministério da Agricultura, Pecuária e Abastecimento. 2009. Regras para Análise de Sementes. Secretaria de Defesa Agropecuária. Brasília, DF: Mapa/ACS, 398 pp.

Marcon, E.C., S.C. Romio, V.M. Maccari, C. Klein \& C.R. Lájus. 2017. Uso de diferentes fontes de nitrogênio na cultura da soja. Revista Thema 14(2): 298-308.

Nogueira, P.D.M., D.G. Sena Júnior \& V.A. Ragagnin. 2010. Clorofila foliar e nodulação em soja adubada com nitrogênio em cobertura. Global Science and Technology 03(02): 117-124.

Parente, T.L., E. Lazarini, S. Caioni \& R.S. Pivetta. 2015. Adubação nitrogenada em genótipos de soja associada à inoculação em semeadura direta no Cerrado. Revista Brasileira de Ciências Agrárias 10(02): 249-255.

Pereira, C.S., M.G. Trentin Filho, I.V.A. Fiorini, H.D. Pereira, J.R. Rocha \& A. Lange. 2018. Formas e estádios de aplicação de adubação nitrogenada no desenvolvimento e produtividade da soja. Revista Agrogeoambiental 10(4): 196-205.

Petter, F.A., L.P. Pacheco, F.A. Neto \& G.G. Santos. 2012. Respostas de cultivares de soja à adubação nitrogenada tardia em solos de cerrado. Revista Caatinga 25(1): 67-72.

Pierozan, C., J.L. Favarin, R.E.M. Almeida, S.M. Oliveira, B.C. Lago \& P.C.O. Trivelin. 2015. Uptake and allocation of nitrogen applied at low rates to soybean leaves. Plant and Soil 39(1-2): 83-94.

Silva, A.F., M.A.C. Carvalho, E.L. Schoninger, S. Monteiro, G. Caione \& P.A. Santos. 2011. Doses de inoculante e nitrogênio na semeadura da soja em área de primeiro cultivo. Bioscience Journal 27: 404-412.

Uhry, D. 2010. Adubação nitrogenada e densidade de semeadura em soja. Dissertação de mestrado. Universidade Federal de Santa Maria - Centro de Ciências Rurais, Santa Maria. 60 pp.

Zimmer, P.D. 2012. Fundamentos da qualidade da semente. In: Peske, ST, FA Villela \& GE Meneghello (Ed.) Sementes: fundamentos científicos e tecnológicos. Pelotas. pp 105-160. 